Tesis. Año 12, 11(13), 2018, 143-159

\title{
Estudios críticos sobre la violencia social, el compromiso político-ciudadano y la veracidad histórica en Noticia de un secuestro (1996)
}

\author{
Jesús Miguel Delgado Del Aguila \\ tarmangani2088@outlook.com
}

\section{Resumen}

Noticia de un secuestro (1996), novela periodística del Premio Nobel de Literatura Gabriel García Márquez, ha permitido que se realicen trabajos hermenéuticos en función de los Estudios Culturales, ya que su contenido abarca períodos históricos de Colombia, la Sociología, la Criminología y la política: todo ello vinculado con la prosa literaria del escritor. En esta oportunidad, lo que represento son tres vertientes de investigación que se han desarrollado sobre la base del estudio de esta obra, las cuales son la manifestación intencionada de la violencia social en Colombia, la constitución del compromiso político-ciudadano y la fidelidad autoral por la exposición histórica en la misma novela. La finalidad de la confrontación y el diálogo intertextual con la crítica literaria es la de establecer un panorama hermenéutico con respecto a lo determinado en Noticia de un secuestro (1996).

Palabras clave: Estado nación, Criminología, Estudios Culturales, interpretación, análisis literario.

\begin{abstract}
News of a Kidnapping (1996), a journalistic novel by the Nobel Prize for Literature Gabriel Garcia Marquez, has allowed hermeneutical works to be carried out according to Cultural Studies, since its content covers historical periods in Colombia, Sociology, Criminology and politics: all linked to the writer's literary prose. On this occasion, what I represent are three aspects of research that have been developed based on the study of this work, which are the intentional manifestation of social violence in Colombia, the constitution of political-citizen commitment and authorial fidelity the historical exhibition in the same novel. The purpose of the confrontation and the intertextual dialogue with literary criticism is to establish a hermeneutical panorama with respect to what was determined in News of a kidnapping (1996).
\end{abstract}

Keywords: National state, Criminology, Cultural Studies, interpreting, literary analysis. 


\section{Estudios críticos sobre la violencia social, el compromiso político-ciudadano y la ve- racidad histórica en Noticia de une secuestro (1996)}

\section{Introducción}

Para esta novela, he clasificado de modo pertinente y cronológico las formulaciones identificables de los autores, para que la hipótesis de esta investigación (la ausencia de un Estado nación en este texto) resulte validada - en algunas instancias, los temas aludidos me han permitido fragmentar ideas y análisis de un determinado crítico literario, para que estos sean regidos según el área de investigación; por tal motivo, se notará que un mismo crítico aborde los distintos tópicos de recepción propuestos.

Para esta sección, solo he compilado investigaciones que fundamentan exclusivamente Noticia de un secuestro (1996), ya que esta delimitación ha sido necesaria, debido a la sobreabundancia de información que hay en torno a estudios críticos de su obra en general, sobre todo de Cien años de soledad (1967), como también, de sus demás novelas y cuentos. Otra precisión más es que he elaborado un balance crítico en función de material bibliográfico que se hallaba a mi disposición: cuento con textos que han sido accesibles desde internet, en la mayoría de los casos; por lo tanto, desconozco la existencia de más información al respecto. Considerando esta premisa, he clasificado convencionalmente a través de los siguientes temas de investigación: la exposición intencionada de la violencia social en Colombia, el fomento del compromiso político y la participación ciudadanos, además de la exigencia autoral por la fidelidad en la representación histórica.

\section{Representación intencionada de la violencia social en Colombia}

Este tema de investigación en la novela es propicio y evidente desde el inicio, en el que acontece el secuestro armado de Maruja y Beatriz, junto con una serie de sucesos violentos que va revelando el período macrocriminal. El secuestro, los asaltos, las torturas, las amenazas o el soborno tienen una atmósfera 
representativa de lo que más se detecta de Noticia de un secuestro: la pérdida de la moral, como también, las repercusiones psicológicas generadas en aquel drama social. Los críticos literarios que desarrollaron este tópico fueron José Luis Méndez ([1989] 2000), Enrique Maza (1996, marzo 16), Enrique Santos Calderón (1996, mayo 5), Tomás E. Martínez (1996), Marta Rivera de la Cruz (1996), Consuelo Triviño Anzola (1996), Isabel Vergara (1998), Rosa Beltrán (1998), Ángel Díaz Arenas (1998), Julio Ariza González (2000), Eugenia Muñoz (1999), Marcela Álvarez (2003, agosto 27), Miguel Cabañas Bravo (2002), Celso José Garza Acuña (2003), Dagmar Ploetz ([1992] 2004), Luis C. Cano (2004), Joana de Fátima Rodrigues (2005), Manuel Cabello Pino (2007), Camila Segura (2007a y 2007b), James Cortés Tique (2008), Edila Paz Goldberg (2008), Melanie Cebrián (2009), Claudia Ospina (2010), C. Buxter (2010), Montserrat Reig Calpe (2012), Josemar Gonçalves Castor (2011), Maruja Pachón, Luzángela Arteaga y María Jimena Duzán (Pachón, Arteaga, Duzán, Cruz \& Pardo, 2016, septiembre 29).

Por ejemplo, José Luis Méndez ([1989] 2000, p. 262) caracteriza a los Extraditables como entidades que son negociables con el Gobierno, a la vez, de ser centrales en la historia de la novela; mientras que Enrique Maza (1996, marzo 16) argumenta que García Márquez elabora el drama, por el hecho de que se introduce en la psicología de los personajes (sobre todo, en el caso de los secuestrados, que sobrevivieron o fallecieron). Enrique Santos Calderón (1996, mayo 5) retoma la propuesta de la revista Newsweek para aludir a que el autor contaba con un interés por dedicar su escritura a aquellos personajes de poder (Pablo Escobar) y su preocupación más bien se centraba en el análisis de temas políticos; asimismo, desarrolla los tópicos relacionados con la violencia y el narcotráfico en Colombia. Tomás E. Martínez (1996) notifica acerca de la existencia de un mundo interno, el cual se va develando hacia el lector mediante la confrontación de los secuestradores con los secuestrados.

Considerando la misma línea de investigación, Marta Rivera de la Cruz (1996) afirma que la historia de Colombia está conformada de víctimas, porque se puede interiorizar en el dolor de los que se hallan privados de libertad, la angustia de sus familias y la tensión de los captores; es decir, la crítica Rivera tiende a configurar a los agentes tratados en función de víctimas. Por otro lado, Consuelo Triviño Anzola (1996, pp. 128-130) hace una descripción inferencial y textual de Noticia de un secuestro; para ello, toma en cuenta los principales agentes de acción que intervienen (víctimas y secuestradores). Asimismo, Isabel Vergara (1998, pp. 76-78) postula que hay una crisis cultural, puesto que la violencia se visualiza a través de los medios sociales y comunicativos; en consecuencia, plantea que se refiere a un estado de emergencia (narcotráfico en Colombia). Rosa Beltrán (1998) enfatiza la victoria en la novela, por más presencia de fuerzas opuestas que polemicen esa realidad y la dosificación que 
se les brinda aparte, ya que hay una reacción y una lucha contra el narcotráfico vivenciado en Colombia, junto con la secuela de captura de Pablo Escobar. Con todo ello, el aporte de Beltrán es el de asumir que en esta obra literaria se igualan condiciones entre el secuestrador y el secuestrado, con la finalidad de priorizar la impotencia que los caracteriza. Sin embargo, Ángel Díaz Arenas (1998, p. 25) atribuye el concepto de víctima a aquellos personajes que fueron secuestrados y fenecieron, tal como ocurrió con Marina Montoya.

Igualmente, para Julio Ariza González (2000, pp. 39 y 44), resulta de su interés la temática de la cultura de la violencia en conexión con la literatura; además, considera que el secuestro sería una modalidad para exponer la violencia en un estado intimidante y cuestionar la configuración propia y particular de los personajes involucrados. Eugenia Muñoz (1999, p. 101) investiga sobre la tradición religiosa y la violencia de Noticia de un secuestro, que estarían presentes en la nueva cultura, mediante los testimonios de aquellos transgresores de la ley (quienes creen en la religión y, a la vez, realizan acciones delictivas). Marcela Álvarez (2003, agosto 27) analiza sintéticamente las conexiones interdisciplinarias en relación con esta novela; para lograr ese trabajo, realiza una validación en torno a la sustentación de fechas, datos históricos y conceptos jurídicos: aquello permite esclarecer el proceso censurador de los medios de comunicación, la conformación del narcoterrorismo y la extradición. Para Miguel Cabañas Bravo (2002, pp. 7-12), la figura del sicario o el asesino en la obra literaria de Gabriel García Márquez, como también, en La Virgen de los sicarios y Rosario Tijeras, sería una alegoría de la violencia endémica en la sociedad colombiana (entidades narcotraficantes y el Gobierno), con la fundamentación de que es la ciudad de Medellín el referente espacial. Asimismo, distingue la moral de los secuestradores en una pervertida y patológica, debido a su contradicción (la religión contra el homicidio). Celso José Garza Acuña (2003, p. 151) argumenta que se trataría de una representación del sufrimiento colombiano, por las condiciones de secuestradores y secuestrados.

Dagmar Ploetz ([1992] 2004, p. 163) afirma que el autor se internaliza en el sufrimiento de los personajes que son secuestrados, con la intención de hacer justicia. Luis C. Cano (2004, p. 420) detecta, en el secuestro de Maruja y la búsqueda emprendida por Villamizar, la dicotomía conflictiva entre el bien (justicia) y el mal (crimen organizado); a la vez, identifica características del relato folclórico, como la soledad de la lucha y el encuentro de ayudantes que posibilitan el rescate exitoso; del mismo modo, Cano alude al gradual enaltecimiento del héroe y la heroína, como aquel resultado del sufrimiento y la superación de las constantes pruebas por las cuales han tenido que atravesar. Joana de Fátima Rodrigues (2005) se refiere a la presencia de violencia en las acciones sociopolíticas, como es el caso de los secuestros. Cabello Pino (2007, p. 2) indica que las vivencias vistas por parte del autor a inicios de 1948, basadas 
en muertes de gran índice, motivaron su creación en función de esa estancia realista. Camila Segura (2007a y 2007b) considera que Noticia de un secuestro es una novela de melodrama, ya que es uno de los discursos dominantes en Latinoamérica: aquello se evidenciaría por el tratamiento de la violencia y la moralidad, que son relucientes por la manifestación del narcotráfico. Esto justificaría la existencia de los estados de inestabilidad e inseguridad de la sociedad colombiana, debido a los períodos polémicos por los cuales atraviesa y que son representados en las novelas de esa etapa.

Por otro lado, James Cortés Tique (2008, pp. 289-290) aborda una explicación biográfica, histórica y periodística para desarrollar parentescos y vínculos entre los personajes, tal como lo hace, por ejemplo, con César Gaviria Trujillo al relacionarlo con sus familiares Gloria Pachón, Maruja Pachón, Alberto Villamizar y Beatriz Villamizar. Para Edila Paz Goldberg (2008) y C. Buxter (2010), se expondrían algunas formas de violencia ejercidas por Pablo Escobar durante la etapa del narcoterrorismo en Colombia. De igual forma, Melanie Cebrián (2009, pp. 65 y 78-80) indica que esta obra literaria muestra la realidad colombiana contemporánea dominada por la violencia; por ejemplo, alude al secuestro. Asimismo, la descripción de las angustias y las emociones generadas en los secuestrados facilitaría la cercanía con el lector; para ello, el autor asociaría la figura retórica de la hipérbole para la exposición física y psicológica de los personajes. Claudia Ospina (2010, pp. 123-125) se interesa en ver la configuración que se le atribuye a Pablo Escobar, como dirigente del Cartel de Medellín y responsable de los diversos sucesos violentos en ese país; además, argumenta que el tema del secuestro le permite al autor hacer referencia al panorama conflictivo por el que atravesaba Colombia (testimonios y datos estadísticos). Reig Calpe (2012, p. 439) fundamenta que es posible la influencia de Sófocles y, sobre todo, de las tragedias tebanas en Noticia de un secuestro, a causa de la construcción de la trama, argumentada en temas de la violencia y el destino; como también, el tratamiento del tiempo y el espacio.

Para concluir con los aportes de la crítica literaria sobre este punto, Josemar Gonçalves Castor (2011) menciona cuál es la trama de esta obra literaria, y enfatiza que predomina más el relato de cómo se desarrolla el secuestro en aquella etapa crítica en Colombia. Maruja Pachón (Pachón, Arteaga, Duzán, Cruz \& Pardo, 2016, septiembre 29) constata en función de la época dramática y trágica que vivió Colombia (logró revivir esa crónica del secuestro), que es manifestada en el texto de Gabriel García Márquez. Luzángela Arteaga (Pachón, Arteaga, Duzán, Cruz \& Pardo, 2016, septiembre 29) sostiene que el autor, para la configuración de esta novela, requería vivenciar aquellas anécdotas que pasaron sus personajes (secuestrados), con el propósito de mimetizar lo acontecido y visibilizarlo en su obra. María Jimena Duzán (Pachón, Arteaga, Duzán, Cruz \& Pardo, 2016, septiembre 29) plantea que la intención de Noticia de un secues- 
tro es que los colombianos puedan sobrellevar su pasado histórico, y que ello se logrará si es que ellos contaran con una capacidad ética al respecto (acerca de la percepción del periodismo, lo político y lo social).

Con respecto a estos planteamientos, inicio con lo estudiado por José Luis Méndez, quien posiciona a los secuestradores (Pablo Escobar, los Extraditables y el Cartel de Medellín) como antagonistas de la democracia: esta distinción permitirá que la dinámica establecida con el Gobierno sea maniquea y comprensible en la novela de García Márquez, puesto que hay una sobreabundancia de datos referenciales.

Por un lado, en función de lo analizado por Enrique Maza, Tomás Martínez y Dagmar Ploetz, concuerdo con la denominación de drama (o melodrama, como postula Camila Segura), ya que este facilita ahondar en los pensamientos de los protagonistas (su mundo interno): esto es propicio, sobre todo, en lo abordado por Enrique Santos Calderón, Miguel Cabañas Bravo y Claudia Ospina, quienes destacan la representación de Pablo Escobar, por encima del proceso de narración de los hechos.

Por otro lado, Rivera de la Cruz, quien identifica específicamente los agentes del orden y el desorden; a su vez, postula de forma generalizante la propuesta de que todos ellos son víctimas. En torno a este caso, sostengo que existen desviaciones de identidad, al punto de que algunos responsables de la seguridad ciudadana se exponen arriesgadamente, además de no cumplir con eficiencia sus roles; no obstante, el factor principal no deja de ser el mismo, aquello que los ha alterado: el narcoterrorismo. Por ello, no serían víctimas, porque se tergiversaría aquella distinción entre victimario y víctima (no se trataría entonces de la victimización en función de muertes, como lo plantea Ángel Díaz Arenas).

La carencia de clasificaciones teóricas y su respectiva fundamentación provocan que el trabajo hecho por Rivera de la Cruz no tenga por finalidad polemizar dentro del área interdisciplinaria. Sobre Consuelo Triviño, resulta inferible afirmar una falta de profundización teórica, debido a que las clasificaciones que hace son superfluas e impresionistas de la lectura: pretende desarrollar mucho en una breve investigación, y únicamente termina mencionando los elementos pertinentes para un análisis utópico. Isabel Vergara sí cuenta con una aproximación más ambiciosa al referirse a Colombia como un país que vive en un "estado de emergencia"; por tal motivo, sería propicio pensar esta obra literaria en función de conceptos interdisciplinarios, como los de macrocriminalidad o semiósfera, con la intención de que se note el proceso de construcción y destrucción del Estado nación de la novela.

Adicionalmente, Rosa Beltrán focaliza de modo apropiado la interacción entre victimario y víctima, la cual es demostrada por la pérdida de autonomía 
y su ubicación en un mismo nivel: esta manera de regularizar el desbalance me facilita indagar al respecto, más adelante, la identidad que se va constituyendo en los personajes, tanto en su forma hablada, actuada y dirigida, como en un espacio determinado. Julio Ariza González y Eugenia Muñoz buscan establecer un vínculo interdisciplinario entre lo ético y lo religioso dentro de aquella seudocultura criminal: estudio que induce a desligar lo criticado de modo tradicional; es decir, se alude a una expectativa óptima en función de lo negativo, similar a lo tratado por María Jimena Duzán, quien reiteraba la idea de que Noticia de un secuestro servía para que el colombiano pudiera reivindicar su propia historia. Marcela Álvarez hace una aproximación inicial de algunos cuantos conceptos jurídicos, aunque son abordados de manera indirecta y algo interpretativa, no por eso deja de delimitar correctamente algunas referencias, como la de los medios de comunicación, el narcoterrorismo y la extradición, articulados de una forma distinta e interdisciplinaria. Por otro lado, resulta oportuna la dualidad indicada por Luis C. Cano (el bien contra el mal), ya que, de allí, se esclarece mejor la estructura con la que se puede empezar a criticar el texto de Gabriel García Márquez. Luzángela Arteaga y James Cortés Tique recurren a lo biográfico, lo histórico y lo anecdótico del autor para validar aquel realismo que permitía garantizar esa trama a la que aluden sus propios personajes.

Los críticos literarios restantes, como Melanie Cebrián, Josemar Gonçalves, Maruja Pachón, Joana de Fátima Rodrigues, Cabello Pino, Edila Paz Goldberg, C. Buxter y Reig Calpe, coinciden en argumentar que es propicia la violencia en aquella etapa crítica de Colombia; no obstante, no hay una clasificación clara y contundente por parte de ellos: la caracterización hecha es muy textual con la consideración de esta novela; en consecuencia, no se logra una confrontación adecuada de índole interdisciplinaria y conforme a los hechos de aquel contexto.

\section{Fomento del compromiso político y la participación ciudadanos}

Implica el sistema en el cual se desenvuelven los gobernantes; en especial, César Gaviria, quien estuvo al mando desde 1990 hasta 1994, de quien se hace más referencia que a otro presidente, como Turbay. A todo ello, se le añade el ajuste en función de los ámbitos jurídico, policial y penal, con la intención de contrarrestar la violencia ejercida por el Cartel de Medellín, a cargo de Pablo Escobar y sus allegados, los Extraditables. Ante esto, se hallan los aportes de Enrique Maza (1996, marzo 16), Julio Ariza González (2000), Robert L. Sims (1999), Marcela Álvarez (2003, agosto 27), Cristo Rafael Figueroa Sánchez ([2000] 2004), Miguel Cabañas Bravo (2002), Dagmar Ploetz ([1992] 2004), Luis C. Cano (2004), María Eugenia Mudrovcic (2005), Nubia Janeth González Ruiz (2006), Camila Segura (2007a y 2007b), James Cortés Tique (2008), Gerald Martin ([2008] 2009), M. Bonzallé Hervé Sakoum (2009), Melanie 
Cebrián (2009), Claudia Ospina (2010), C. Buxter (2010) y Maruja Pachón (Pachón, Arteaga, Duzán, Cruz \& Pardo, 2016, septiembre 29), los cuales se explicarán a continuación.

Primero, Enrique Maza (1996, marzo 16) contextualiza con referentes históricos y periodísticos la función que tuvieron los presidentes de Colombia, junto con las polémicas generadas por las modificaciones y las imposiciones de las leyes que contrarrestaban el continuo terror de los Extraditables; por ejemplo, hace recordar que, en el período crítico existente en Colombia por el narcotráfico, mostrado en Noticia de un secuestro, había necesidad de incorporar soluciones internacionales para reducir el panorama de violencia y delicción; sin embargo, la atmósfera de peligro impedía que el Gobierno pudiera realizar acciones efectivas; por lo tanto, se retrasaba y se veía inaccesible la orden de extradición a Estados Unidos del Cartel de Medellín (que incluía a Pablo Escobar). Julio Ariza González (2000, pp. 39-40) afirma que hay mayor interés en el texto de Gabriel García Márquez por su trasfondo (la producción, lo intelectual, lo ideológico, lo biográfico y lo histórico), y no tanto por su contenido, su trama o su asunto; en consecuencia, existiría una dinámica de querer mantener en tensión la memoria en correlación con la historia, como también, el vínculo entre el escritor y sus testigos. Robert L. Sims (1999) propone que, a pesar de que los medios de comunicación son posibles, no hay acceso directo hacia ellos. Marcela Álvarez (2003, agosto 27) muestra una actitud similar: rechaza toda forma visible de prensa en la novela, asimismo, de la democracia. Para desarrollar su fundamentación, se vale de la Constitución de Colombia de 1991, en la que se enfatiza la importancia de la libertad de prensa, junto con la preponderancia de la comunicación para un Estado.

Posteriormente, Cristo Rafael Figueroa Sánchez ([2000] 2004, p. 106) sostiene que esta obra literaria busca la representación de los órganos que intervinieron en ese suceso colombiano (el Gobierno, los grupos militares, etc.). $\mathrm{Mi}$ guel Cabañas Bravo (2002, p. 10) plantea que el autor no intenta culpabilizar a Pablo Escobar como responsable, sino mostrar el panorama violento y conflictivo, en el que se evidencia cómo los narcotraficantes se incorporan en las altas esferas políticas: todo ello con la finalidad de que el lector mismo extraiga su propia percepción. En cuanto contenido político, Dagmar Ploetz ([1992] 2004, p. 162) formula que el tema del libro es el terrorismo y la lucha por la destrucción de las estructuras democráticas y del Estado de derecho que generan los narcotraficantes. Luis C. Cano (2004, pp. 427-428) admite que, en Noticia de un secuestro, los medios de comunicación sirven como una vía entre los secuestradores y los secuestrados sobre el Estado; igualmente, sería una herramienta de información, reflexión y cultura. María Eugenia Mudrovcic (2005, p. 166) reconoce un vínculo entre Gabriel García Márquez y Michel Foucault: precisa que la censura cumple un rol elogiador en el autor; por tal motivo, habría un 
compromiso riesgoso al desarrollar un discurso literario de la modernidad en los medios.

Luego, Nubia Janeth González Ruiz (2006) deduce que Colombia, como cada país, posee particularidades que lo identifican (presencia del artista con su país y su público), a través del lenguaje; además de ser hiperbólico en la configuración de sus personajes (debido a que internaliza en las diversificaciones del mal) y elogiador por referirse a la idiosincrasia colombiana como aquel fascinante (El Dorado), donde se hallan riquezas que ofrecen dignas maneras de participar en la humanidad. Camila Segura (2007a y 2007b) propone que esta obra literaria incita a la ciudadanía (caracterizada por el lector) a adoptar una postura política colectiva (maniquea) sobre la violencia de ese período caudillesco y marginal; a la vez, asumir la reconciliación entre las personas (inocentes y culpables), como una solución sociohistórica que se iniciaría del imaginario colombiano. James Cortés Tique (2008, pp. 271-275) manifiesta que, en esta, se cuenta con la expectativa de que el lector comprenda el caos social durante la crisis política de Colombia; para ello, el autor, quien sería honesto y responsable, cumple el rol de mediador entre el poder político y la instancia ciudadana (u opinión pública), con la finalidad de investigar y denunciar la opacidad de la esfera del poder (antidemocrático). A su vez, plantea que el objetivo de los secuestros era ejercer una presión hacia el poder político por parte del Cartel de Medellín, para que se anulara la cláusula contra la extradición a los narcoterroristas. Gerald Martin ([2008] 2009, p. 521) identifica la representación de la clase media alta, mediante el tipo de personajes que se desenvuelve en la novela. También, M. Bonzallé Hervé Sakoum (2009, p. 410) infiere que el autor sería un rebelde, puesto que está acusando y delatando las manifestaciones violentas que atraviesa Colombia en ese contexto.

Finalmente, Melanie Cebrián (2009, p. 3) señala que a través de Noticia de un secuestro se busca la reivindicación de la realidad. De igual forma, Claudia Ospina (2010, p. 124) señala que, en relación con la política, hay un intento frustrado de los Extraditables en insertarse en el poder. C. Buxter (2010) duda sobre la reputación que tienen los funcionales de la política en Colombia, a partir de esta novela, junto con la seguridad garantizada. Asimismo, Maruja Pachón (Pachón, Arteaga, Duzán, Cruz \& Pardo, 2016, septiembre 29) cuenta con la concepción de que esta obra literaria muestra la lucha contra el narcotráfico, junto con la forma de pactar del Gobierno con la mafia: aquello lo haría de un modo tan cuidadoso, por lo que se esclarece su rol de periodista comprometido, y el producto generado sería una reivindicación civil del Periodismo.

Los planteamientos de los críticos literarios, articulados en los párrafos anteriores, exponen temáticas que fundamentaré posteriormente en mi investigación. 
Primero, para Enrique Maza, Julio Ariza González, Miguel Cabañas Bravo, Dagmar Ploetz y M. Bonzallé Hervé Sakoum, importa cómo se representa el trasfondo violento de Noticia de un secuestro (lo ideológico y lo histórico), con la finalidad de que el lector construya su propia interpretación. Sobre esa intención, Camila Segura y James Cortés Tique han coincidido; al igual que Melanie Cebrián, quien detecta que todo ello conducirá a la reivindicación de la realidad. Esa ideología a posteriori tan solo se puede asegurar si es que se asimila que ha existido un tránsito de lo antinacional a lo nacional, que se visibilizaría mediante una configuración de un Estado demócrata e imparcialmente legalizado por las autoridades.

Segundo, retomando lo argumentado por Robert L. Sims y Marcela Álvarez, se infiere un interés interdisciplinario por la parte jurídica y antropológica, aunque su objeto de estudio no sea la macrocriminalidad, sino los medios de comunicación en la Colombia formulada en la novela; asimismo, se hace una teorización bien aplicada en torno a esos mecanismos que perturban la libertad y la democracia: parámetros propios para esta investigación, sobre la base de la macrocriminalidad y los organismos del orden.

Tercero, a Cristo Rafael Figueroa Sánchez, Claudia Ospina, C. Buxter y Maruja Pachón, les importa las interrelaciones existentes entre los órganos que intervinieron en ese conflicto colombiano por el poder (el Gobierno, los grupos militares, los Extraditables, etc.); además, aquello aseguraba la desconfianza y la inseguridad provocadas en la ciudadanía. Desde mi punto de vista, este sería un indicador para proponer la ausencia de un Estado nación, puesto que las leyes se adaptan a un tipo de personas, y las negociaciones no resultan ser explícitas por parte del Gobierno colombiano.

Cuarto, Luis C. Cano distingue los medios de comunicación más como una vía de conexión entre el Estado y quienes se configuran como secuestradores y secuestrados, la cual sirve como herramienta que se usaría para hacer referencia al modo de interacción entre victimario y víctima. Sobre ello, la utilidad de la prensa es desplazada a una denominación como canal, mas no interviene ni se involucra en el desarrollo de los hechos sociales.

Quinto, con Mudrovcic, la propuesta se centraliza en cómo es percibido el autor en los medios de comunicación; por tal motivo, allí, se revela específicamente la importancia que ejerce la censura. Al igual que el punto anterior, se refuerza la idea de que su intervención resulta dramática, desde afuera, aunque satisface a su público en la necesidad de mantener a una sociedad informada.

Sexto, estoy en contra con González Ruiz al aludir al tema de hiperbólico, ya que esta definición implica una exageración de lo ocurrido: acción que no es visible en el texto de Gabriel García Márquez, sino que persiste un deseo por 
mostrar la mímesis de la realidad; no obstante, sí me hallo a favor cuando él trata la idiosincrasia de Colombia, de la que se presencian mecanismos que han sido productivos y buenos para su organización social.

Para finalizar, en torno a lo articulado por Gerald Martin, es necesario establecer una estructuración de las clases sociales para que pueda analizarse correctamente el contenido de la novela: el crítico llega a identificarlas.

\section{Exigencia autoral por la fidelidad en la representación histórica}

Si bien la hipótesis de mi trabajo de investigación sería la de hallar la ausencia del Estado nación en la sociedad colombiana en los últimos dos decenios del siglo XX, este apartado (junto a los tres siguientes) explicaría ciertas bases que no podrían obviarse para la validación de la contextualización. Esta clasificación parte de la idea de que esta novela es asumida como un referente histórico, el cual nos permite conocer cómo fue la sociedad de ese entonces, como también, algunos movimientos culturales y míticos. Los representantes de esta propuesta son José Luis Méndez ([1989] 2000), Manuel Antonio Arango (1991), Enrique Santos Calderón (1996, mayo 5), Ángel Díaz Arenas (1998), Julio Jensen (2001), Pablo García Dussán (2003), Celso José Garza Acuña (2003), Nubia Janeth González Ruiz (2006), Gerald Martin ([2008] 2009), Melanie Cebrián (2009), Jeanette Gonsior (2011), Luzángela Arteaga y Rodrigo Pardo (Pachón, Arteaga, Duzán, Cruz \& Pardo, 2016, septiembre 29).

Para iniciar, José Luis Méndez ([1989] 2000, p. XI) fundamenta que García Márquez expone el drama acaecido a los colombianos del modo más objetivo, en relación con un período crítico de la historia de su país (político y social), en el que el narcotráfico está imperando. También, Manuel Antonio Arango (1991, pp. 7-9) hace un análisis vinculado con la historia y la cultura para explicar cómo se desarrollan la intrahistoria y el mito, los cuales resultarían de utilidad para la formación de un arquetipo del inconsciente colectivo. Del mismo modo, se centra en ese argumento para clasificar la tradición simbólica y literaria a la cual alude el autor al momento de expresar la historia y la cultura de su país. Enrique Santos Calderón (1996, mayo 5) menciona que en esta novela el autor representa un realismo crudo, brutal y minuciosamente documentado, por lo que la realidad superaría a la ficción. El abordaje que emplea Ángel Díaz Arenas (1998), en general, aporta con la reescritura de Noticia de un secuestro (1996), pero de una manera explicativa y extensa, con patrones históricos, periodísticos y biográficos, además de asociarlos con acontecimientos latinoamericanos semejantes, como lo ocurrido con la operación Chavín de Huántar en Perú; por lo tanto, la destreza del autor se basaría en el tratamiento objetivo de la constitución de una crónica, con cierta subjetividad como narrador. 
Asimismo, el crítico Julio Jensen (2001, p. 128) sostiene que se expone un "período extremadamente cruento en la historia de Colombia". Pablo García Dussán (2003, p. 134) formula que este texto corresponde con lo que pasó realmente en su país, en cuanto imaginario social y búsqueda de una identidad, junto con las políticas neoliberales y la globalización que atraviesa América Latina. De igual forma, Celso José Garza Acuña (2003, p. 159) argumenta que el autor hace una reconstrucción de diálogos de los protagonistas para otorgarle una mayor veracidad a los hechos. Nubia Janeth González Ruiz (2006, p. 14) se centra en los sucesos verídicos y comprobables de la obra literaria, ya que, por medio de estos, se genera una imagen más cercana a la realidad latinoamericana (esta sería el motivo por el que Colombia se mostraría de modo más explícito mediante sus textos). Por otro lado, Gerald Martin ([2008] 2009, p. 527) recurrió a la investigación y las entrevistas para construir, de forma objetiva y real, Noticia de un secuestro.

A su vez, Melanie Cebrián (2009, p. 76) analiza la configuración histórica de esta novela, junto con Cien años de soledad y El general en su laberinto; a su vez, admite que el autor demuestra su afinidad por plantear detalles de manera objetiva. Jeanette Gonsior (2011, p. 2) determina que la incorporación de elementos sociales y políticos es propia de la historia y la literatura de Colombia y que el autor busca reconstruir del modo más realista y preciso para que se evidencien los hechos generados por los narcotraficantes colombianos. Luzángela Arteaga (Pachón, Arteaga, Duzán, Cruz \& Pardo, 2016, septiembre 29), detecta que lo importante en el texto de Gabriel García Márquez es mostrar la verdad, sin que el autor posea afinidad por una posición. Rodrigo Pardo (Pachón, Arteaga, Duzán, Cruz \& Pardo, 2016, septiembre 29), enfatiza el interés del escritor por el detalle, la documentación y la investigación; por ello, hace alusión a la preferencia que poseía él en contarlo mejor y no en narrarlo por primera vez, como se ve en el proceso de redacción de esta novela. Para conseguirlo, frecuentará conceptos periodísticos desde lo literario, que se revelan ya en los títulos de sus libros, como "noticia", "relato", "crónica".

En relación con lo investigado por la crítica literaria, la apreciación que se tiene en general es la de indagar en torno a la historia como un referente de la novela que permitiría reafirmar una impresión de credibilidad: una necesidad que se justifica por la verificación y la confrontación entre ficción y realidad. Al respecto, a José Luis Méndez, Gerald Martin, Melanie Cebrián, Enrique Santos Calderón, Ángel Díaz Arenas, Nubia Janeth González Ruiz, Jeanette Gonsior, Luzángela Arteaga y Rodrigo Pardo, les importaba la objetividad, mientras que Arango se vale de otros referentes, como los de la cultura y la historia social; sin embargo, mis intereses no buscan cuestionar qué grado veracidad hay en Noticia de un secuestro (1996), ya que asumo esta novela como un texto que, efectivamente, cuenta con una configuración histórica que concuerda con 
la realidad (aquello me facilita establecer otros nexos: ya no Literatura-Historia, sino Literatura con Sociología, Antropología, Derecho, Criminología). Los críticos Julio Jensen y Pablo García Dussán asociaban estos sucesos con la construcción de un imaginario social y una identidad: planteamiento que retomaría conceptos mayormente subjetivos y sociológicos, más que la reafirmación de la existencia de los hechos. Asimismo, asumo que los diálogos y la descripción de las situaciones están trastocados (Celso José Garza Acuña enfatizaba sobre la fidelidad en la constitución de los diálogos de los protagonistas, únicamente para comprobar la verdad); como también, la incompletitud de los sucesos históricos narrados. Estas bases me permiten reincidir en el tema de la macrocriminalidad; con ello, sostener una fundamentación ética e interdisciplinaria.

\section{Conclusiones}

El trabajo hermenéutico literario extraído de Noticia de un secuestro (1996), en relación con los tres tópicos investigados (la exposición intencionada de la violencia social en Colombia, el fomento del compromiso político-ciudadano y la exigencia autoral por la fidelidad en la representación histórica), representa de manera diversificada la posición que adoptan los críticos en función del período macrocriminal por el que atraviesa Colombia durante las manifestaciones delictivas y seudopolíticas de Pablo Escobar, junto con el Cartel de Medellín. Por tal motivo, explicaré las tres premisas que sintetizan los aportes expuestos.

Primero, se cuestionó la importancia que requería un análisis literario en textos como el de Noticia de un secuestro (1996), ya que los vínculos interdisciplinarios implican también una profundización sobre categorías que se manejan internamente. Muy aparte de la historia y los referentes legales que se presentan en el texto, el dramatismo y la inestabilidad ética y conductual que expone el autor a sus personajes (mediante sus acciones, sus diálogos o sus ideologías) brindan realismo; pero, algo más importante, nos permite conocer y ahondar en la psicología del criminal, la víctima, el político, etc.; por lo tanto, su veridicción no es valiosa en cuanto es más fidedigna con los hechos ocurridos, sino que resulta importante la configuración particular y única que hace de los personajes. Esa variabilidad y ese dinamismo en la identidad de los mismos van desarrollando una tensión y una expectativa exclusivas para el lector, por el afán mismo de percibir una incompletitud narrativa.

Segundo, con respecto al fomento del compromiso político-ciudadano mediante Noticia de un secuestro (1996), se dedujo que la hermenéutica ha coincidido indirectamente en que las estructuras que conforman la sociedad en su conexión con el Estado no se hallan bien establecidas: se cuenta con medios periodísticos que dramatizan la información, como también, parcializan la objetividad de la noticia por el hecho de sentirse condicionados a mostrar la re- 
lación narcoterroristas-víctimas del Estado. De esa manera, el reduccionismo sociopolítico a negociaciones que no son explícitas para conocimiento de la sociedad colombiana producirá favoritismos y una seguridad ciudadana dependiente del éxito de esos tratados ilícitos.

Tercero, en cuanto a la necesidad de que existan referentes históricos en la novela de Gabriel García Márquez para validar la objetividad y la credibilidad, no resulta oportuno analizarla de esa manera, puesto que una investigación literaria no puede basarse prioritariamente en comparar, afirmar o negar lo que sí ocurrió o lo que no, ya que lo predominante es aprovechar la condición de la novela, como objeto artístico, invención o ficción, para establecer e iniciar la crítica sobre la base de lo que ofrece su discurso: vínculos interdisciplinarios evidentes (Historia, Sociología, política, Literatura, Criminología, Derecho, etc.).

\section{Agradecimientos}

Este trabajo es parte de la tesis Ausencia de un Estado nación en Noticia de un secuestro (1996), a partir de un periodo de macrocriminalidad (últimos dos decenios del siglo XX en Colombia), desarrollada en la Maestría en Literatura Peruana y Latinoamericana con mención en Estudios Culturales por la Universidad Nacional Mayor de San Marcos (UNMSM / Lima-Perú).

\section{Referencias bibliográficas}

Álvarez, M. (2003, agosto 27). Libertad de prensa. Noticia de un secuestro de Gabriel García Márquez. Monografias. Recuperado de https://goo.gl/zNPN91 [16 de diciembre de 2017].

Anónimo (2007). Noticia de un secuestro (resumen). Recuperado de https://goo.g1/ zSErss [16 de diciembre de 2017].

Anónimo (2012). Noticia de un secuestro (sinopsis). Recuperado de https://goo.g1/ $\mathrm{KaKsVO}$ [16 de diciembre de 2017].

Arango, M. (1991). La intrahistoria y lo mítico, elementos de protesta social en la narrativa de Gabriel García Márquez. Castilla: Estudios de Literatura, (16), 7-17.

Ariza, J. (2000). Noticia de un secuestro o los límites de la ficcionalidad. Actas del XIII Congreso de la Asociación Internacional de Hispanistas, 3, 38-45.

Beltrán, R. (1998). Licencias y reticencias de un estilo (sobre Noticia de un secuestro). XX Congreso Nacional de Literatura y Semiótica: "Cien años de soledad" treinta años después. Recuperado de https://goo.gl/OJJnhx [16 de diciembre de 2017].

Buxter, C. (2010). Noticia de un secuestro, de Gabriel García Márquez. Recuperado de https://goo.gl/WIORR4 [16 de diciembre de 2017]. 
Cabañas, M. (2002). El sicario en su alegoría: la ficcionalización de la violencia en la novela colombiana de finales del siglo XX. Taller de Letras, (31), 7-20.

Cabello, M. (2007). Amor y peste en Albert Camus y en Gabriel García Márquez. En Dominique, M. \& Duchêne, N. (Coords.). Littérature, langages et arts: rencontres et création. Recuperado de http://dialnet.unirioja.es/descarga/articulo/2554314.pdf [16 de diciembre de 2017].

Cano, L. (2004). Noticia de un secuestro de Gabriel García Márquez: entre el cuento popular y el reportaje. Revista Iberoamericana, $L X X(207)$, 419-430.

Cebrián, M. (2009). Representación histórica en la obra de Gabriel García Márquez. Hamburgo: Diplomica Verlag.

Cortés, J. (2008). Noticia de un secuestro entre la mentira política y la ficción mercenaria. Poligramas, (30), 269-301.

Díaz Arenas, Á. (1998). Reflexiones en torno a "Noticia de un secuestro" de Gabriel García Márquez (la historia y sus limites). Kassel, Alemania: Edition Reichenberger.

Figueroa, C. (2004 [2000]). Gramática-violencia: una relación significativa para la narrativa de segunda mitad del siglo XX. Tabula Rasa, (2), 93-110.

García Dussan, P. (2003). La narrativa colombiana actual: una literatura "tanática”. Cuadernos de Literatura, 9(17), 131-137.

García Márquez, G. (1996). Noticia de un secuestro (1. ${ }^{a}$ ed.). Bogotá: Editorial Norma.

Garza, C. (2003). Vigencia del relato como sentido de la realidad: análisis de reportajes históricos (Tesis de doctorado, Madrid, España, Universidad Complutense de Madrid).

Gonçalves, J. (2011). La vida y la obra de Gabriel García Márquez. Recuperado de https://www.sapili.org/livros/es/ea000939a.pdf (pp. 1-17).

Gonsior, J. (2011). Gabriel García Márquez. "Noticia de un secuestro" im Spannungsfeld zwischen Journalismus und Literatur. Múnich, Alemania: Grin Verlag.

González, N. (2006). Colombia en la pintura de Fernando de Botero. El realismo mágico en el imaginario Boteriano (Tesis de doctorado, Barcelona, Departament de Composició Arquitectònica, Escola Tècnica Superior d'Arquitectura de Barcelona, Universitat Politècnica de Catalunya).

Hervé, M. (2009). Analyse sociocritique de Relato de un naufrago et de Noticia de un secuestro de Gabriel Garcia Marquez (Tesis de doctorado, Limoges, Francia, Universidad de Limoges).

Jensen, J. (2001). ¿Realismo mágico o literatura del testimonio? En torno a Noticia de un secuestro de Gabriel García Márquez. En Naranjo, J. y Enkvist, I. (Eds.). Pensadores y escritores hispánicos. Lund, Suecia: Heterogénesis (pp. 125-134). 
Martin, G. (2009 [2008]). Gabriel Garcia Marquez. A life. Londres: Bloomsbury Publishing.

Martínez, T. (1996). Noticia de un secuestro: el revés de la trama. Cambio 16, (155), 36-37.

Maza, E. (1996, marzo 16). El narcotráfico colombiano, en el nuevo libro de Gabriel García Márquez. Proceso. Recuperado de https://goo.gl/46MSRt [16 de diciembre de 2017].

Méndez,J. L.(2000 [1989]). Cómo leer a García Márquez: una interpretación sociológica (3. ${ }^{\mathrm{a}}$ ed.). Puerto Rico: Editorial de la Universidad de Puerto Rico (EDUPR).

Mudrovcic, M. (2005). Nombres en litigio. Velasco vs. García Márquez. Arizona Journal of Hispanic Cultural Studies, (9), 161-170.

Muñoz, E. (1999). Tradición religiosa y cultura de la violencia en Noticia de un secuestro y La Virgen de los sicarios. MIFLC Review, (8), 99-112.

Ospina, C. (2010). Representación de la violencia en la novela del narcotráfico y el cine colombiano contemporáneo (Tesis de doctorado, Kentucky, Universidad de Kentucky).

Pachón, M., Arteaga, L., Duzán, M. J., Cruz, J. \& Pardo, R. (2016, septiembre 29). Festival Gabo - Jueves 29 de septiembre [Tarde] Telemedellín [video]. Recuperado de https://youtu.be/H1fqIxFL8_w [16 de diciembre de 2017].

Paz, E. (2008). Enfoque analítico de la obra narrativa de Gabriel García Márquez. Aproximación a la ideología de sus textos (Tesis de doctorado, Salamanca, Universidad de Salamanca, Facultad de Filología, Lengua Española).

Ploetz, D. (2004 [1992]). Gabriel García Márquez (Trads. G. Lapiedra y A. Valero). Madrid: Edaf.

Reig, M. (2012). La creación del espacio trágico en la obra de Gabriel García Márquez. Synthesis, (19), 43-61.

Rivera, M. (1996). Noticia de un secuestro. El regreso anunciado del cronista. Espéculo. Recuperado de http://pendientedemigracion.ucm.es/info/especulo/numero3/ gmarquez.htm [16 de diciembre de 2017].

Rodrigues, J. (2005). Literatura e jornalismo em Gabriel García Márquez: uma leitura de crônicas. (Tesis de maestría, São Paulo, Universidade de São Paulo).

Santos, E. (1996, mayo 5). Noticia de un secuestro. El Tiempo. Recuperado de https:// goo.gl/TKsDCB [16 de diciembre de 2017].

Segura, C. (2007a). Violencia y melodrama en la novela colombiana contemporánea. América Latina Hoy, 47, 55-76.

Segura, C. (2007b). Asimilación de un paisaje trágico: violencia y melodrama en la novela colombiana contemporánea (Tesis de doctorado, Nueva York, Universidad de Colombia). 
Sims, R. (1999). El molino a secuestro: narración, violencia y fictualidad en Noticia de un secuestro de García Márquez y ¡Secuestrados! La historia por dentro de Juan Vitta. Revista de Estudios Colombianos, (19), 54-68.

Triviño, C. (1996). Noticia de un secuestro. Del realismo mágico al realismo macabro. Cuadernos Hispanoamericanos, (556), 127-131.

Vergara, I. (1998). Noticia de un secuestro: la historia como horror apocalíptico. XX Congreso Nacional de Literatura y Semiótica: "Cien años de soledad" treinta años después. Recuperado de https://goo.g1/U3EENq [16 de diciembre de 2017]. 